\title{
Particulate matter in the rural settlement during winter time
}

\author{
Tomasz Olszowski ${ }^{1, *}$ \\ ${ }^{1}$ Department of Thermal Engineering and Industrial Facilities, Opole University of Technology, Mikołajczyka 5, 45-271 Opole, \\ Poland
}

\begin{abstract}
The objective of this study was to analyzed the variability of the ambient particulates mass concentration in an area occupied by rural development. The analysis applied daily and hourly $\mathrm{PM}_{2.5}$ and $\mathrm{PM}_{10}$ levels. Data were derived on the basis of measurement results with the application of stationary gravimetric samplers and optical dust meter. The obtained data were compared with the results from the urban air quality monitoring network in Opole. Principal Component Analysis was used for data analysis. Research hypotheses were checked using U Mann-Whitney. It was indicated that during the smog episodes, the ratio of the inhalable dust fraction in the rural aerosol is greater than for the case of the urban aerosol. It was established that the principal meteorological factors affecting the local air quality. Air temperature, atmospheric pressure, movement of air masses and occurrence of precipitation are the most important. It was demonstrated that the during the temperature inversion phenomenon, the values of the hourly and daily mass concentration of $\mathrm{PM}_{2.5}$ and $\mathrm{PM}_{10}$ are very improper. The decrease of the PM's concentration to a safe level is principally relative to the occurrence of wind and precipitation.
\end{abstract}

\section{Introduction}

During the cold months of the year, anthropogenic activity leads to a considerable deterioration of air quality [1]. This situation is particularly relevant for geographical the area of the former Eastern Bloc, where household heating is based on useful energy supply from outdated systems. This problem is however, not limited only to urban areas $[2,3]$. In the areas of compact rural settlement, the ratio of solid fuels combustion in the total production of thermal energy is in the range from 70 to $95 \%$ [4]. Unfortunately, papers discussing the results of research on air quality in rural areas are scarce [5].

It's widely known, that in Poland, the air quality is worse during the cold season than in warm [6]. In the cold season, the main source of ambient aerosol is uncontrolled emission from local individual heating systems. These systems are commonly outdated, which leads to the larger degree of enriching the troposphere with a load of hazardous substances.

Among the air pollutants, particulate matter (PM) has the greatest impact on the quality of the environment. This effect can be attributed to the large load and chemical properties of the emitted particles. As it contains a variety of hazardous substances deposited on its surface, suspended particulate matter is known to have a negative impact on the health of humans and local conditions of the microclimate. The group of the most hazardous includes fine particles, formed by the particles of up to 2.5 micrometers in diameter $\left(\mathrm{PM}_{2.5}\right)$. Such fine particles can penetrate into the blood vessels and human organs following the processes of inhalation and gas exchange. As given in [6]: knowledge of the possible origin of $P M_{2.5}$ is still incomplete. There is a limited number of appropriate $P M_{2.5}$ sampling points in Central and Eastern Europe which substantially restricts accurate identification of PM sources." Equally, the information regarding the ratio of fine particles in $\mathrm{PM}_{10}$ (i.e. ones with the aerodynamic diameter $<10 \mu \mathrm{m}$ ) is scarce. This ratio is often considered as the principal indicator of the air quality in terms of the particulate matter mass concentration alongside with heavy metal and PAH's.

Due to the scarcity of reports into the condition of troposphere in the areas of Central and Eastern Europe in the cold season, a study into the variability of the concentrations of $\mathrm{PM}_{2.5}$ and $\mathrm{PM}_{10}$ was undertaken. The main objective of this study was to analyzed the variability of the ambient particulates mass concentration in an area occupied by rural development. The objective of this study was to determine the ratio of the fine fraction in $\mathrm{PM}_{10}$ and a comparison between air quality in the rural and urban areas.

The scope of a research project in this area involved the verification of a hypothesis regarding the equal ratios of $\mathrm{PM}_{2.5}$ in $\mathrm{PM}_{10}$ in the areas with different areas of urban development. The hypothesis was verified for the conditions of smog occurrence and during the periods when it was absent. In addition, the study led to the substantiation of the hypothesis regarding the impact of meteorological parameters on the air quality in the areas of rural development.

\section{Materials and methods}

\subsection{Measurement site}

Corresponding author: t.olszowski@po.opole.pl 
The main research was conducted in rural area over 3 cold seasons (2015-2017). The registration of meteorological parameters and concentration of $\mathrm{PM}_{2.5}$ and $\mathrm{PM}_{10}$ in the rural area were realised in the centre of village Kotórz Mały (Poland, 50 43' 50" N; $18^{\circ} 02^{\prime} 36^{\prime \prime}$ E; 1025 inhabitants). The measurement point was located in direct neighborhood of compact rural building development area.

The objective of a comparison of two areas with different levels of urban development, the work applied data from a town measurement station managed by The Voivodeship Inspectorate of Environmental Protection [7]. The meteorological data representative of a urban area and concentration of PM's were determined in provincial town of Opole (Poland, 50 40' $13^{\prime \prime} \mathrm{N}$; $17^{\circ} 55^{\prime}$ $12^{\prime \prime} \mathrm{E}, 122,000$ inhabitants). The monitoring station was situated in the centre of the city, near low and high residential housing and commercial development. Measurement point was situated $12 \mathrm{~km}$ south-west from the observation point in Kotórz Mały.

The tested zone in the village is characterized by low buildings, which predominantly use obsolete individual heating systems (coal, in a proportion of $91 \%$ ). In the urban area, the ratio of the individual household heating systems is considerable smaller. Within the radius of 1 $\mathrm{km}$ from the measurement spot, over $60 \%$ of buildings apply district heating.

\subsection{Measurements procedure and results analysis}

Simultaneous 24-hour aspiration of the $\mathrm{PM}_{2.5}$ and $\mathrm{PM}_{10}$ was carried out with two PNS3D15 low-volume dust meters. Aspirations were conducted by 91 days of each winter. The aspiration headers were installed $2 \mathrm{~m}$ above ground. The apparatus were located 5 meters apart. The PM separators were applied with Whatman GF/A fibreglass air filters with a diameter of $47 \mathrm{~mm}$. Prior to and after aspiration, the filters were seasoned over $24 \mathrm{~h}$ in conditions of constant temperature and humidity and, subsequently, their weight was determined by a differential scale (RADWAG XA 52/2X). The procedure for estimating the aerosol mass concentration was conducted in accordance with guidelines of the European Standard [8]. The expanded concentration measurement of uncertainty (U) did not exceed 3.6\%.

Hourly aspirations of aerosols in rural area were provided with using the DustTrak DRX 8533 Aerosol Monitor TSI ${ }^{\circledR}$. The measurement procedure was realized by application of the guidelines given by the manufacturer [9]. Hourly registrations were conducted only in January 2017.

To assess the meteorological conditions, two portable weather stations were used (Davis Vantage $($ )). Values of main parameters (temperature $(\mathrm{T})$, atmospheric pressure (P), relative humidity (RH), wind speed (W), precipitation $(\mathrm{R})$ and duration of sunshine $(\mathrm{S})$ ) were collected with data-logger.

The raw data was verified by the Shapiro-Wilk test with the purpose of determination of the distribution of the measurement data. The data did not demonstrate normal distribution, hence, the analysis of the registered data was performed by the use of a non-parametric test. The comparison of the results applied Mann-Whitney U test. The data applied for statistical analysis was rescaled in accordance with the algorithm (1), which reduced the impact of the absolute value of a given variable and enabled all variables to be limited within the range $\{0 ; 1\}$.

$$
X^{\prime}=\frac{X-X_{\min }}{X_{\max }-X_{\min }}
$$

The relationships between variables were examined using Spearman correlation [10]. Significance level of 0.05 was adopted. Finally, the study used Principal Component Analysis (PCA). The PCA is a technique used to emphasize variation and bring out strong patterns in a dataset. It's often used to make data easy to explore and visualize. A detailed description of the procedures for implementing the PCA is shown at work [11].

\section{Results and discussion}

Table 1 contains a summary of data regarding selected meteorological parameters registered during the 3 -seasons observations in rural area. Throughout three successive winters, the mean temperature was slightly above the multi average measured over many years. The atmospheric pressure and relative humidity were characterized by the lowest variability coefficients $(0.01$ and 0.12 , respectively) and their mean values were characteristic for the analyzed period. The wind speed and hydrometeor precipitation was associated with the occurrence of variable weather conditions. The meteorological condition was determined by the occurrence of the high pressure area with a center located in Russia (considerable insolation, windless weather, lack of precipitation - on average $23 \%$ of the winter period) and western recirculation (area associated with occurrence of rainfall, higher temperature, lack of insolation, low pressure, considerable movement of air masses). During the examined period, the values of meteorological parameters registered in the weather station located in the city were statistically almost identical to the ones registered in the rural areas ( $p$ values for the Mann-Whitey test: $0.11(\mathrm{~T}) ; 0.09(\mathrm{RH})$; $0.18(\mathrm{~W}) ; 0.19(\mathrm{P}) ; 0.17(\mathrm{R})$; and $0.44(\mathrm{~S}))$.

Table 1. Meteorological parameters characterising the conditions during the observations.

\begin{tabular}{|c|c|c|c|c|}
\hline parameter & MIN & MAX & AVG & SD \\
\hline $\mathrm{PM}_{2.5}\left[\mu \mathrm{g} \cdot \mathrm{m}^{-3}\right]$ & 8.00 & 142 & 31.9 & 29.8 \\
\hline $\mathrm{PM}_{10}\left[\mu \mathrm{g} \cdot \mathrm{m}^{-3}\right]$ & 11.0 & 195 & 44.6 & 34.8 \\
\hline $\mathrm{T}\left[{ }^{\circ} \mathrm{C}\right]$ & -12.2 & 11.7 & 1.75 & 4.22 \\
\hline $\mathrm{RH}[\%]$ & 59.1 & 96.4 & 80.0 & 9.65 \\
\hline $\mathrm{W}[\mathrm{m} / \mathrm{s}]$ & 0.00 & 16.1 & 3.06 & 9.71 \\
\hline $\mathrm{P}[\mathrm{hPa}]$ & 978 & 1041 & 1016 & 11.4 \\
\hline $\mathrm{R}[\mathrm{mm}]$ & 0.00 & 14.0 & 1.39 & 2.63 \\
\hline $\mathrm{S}[\mathrm{h}]$ & 0 & 9.3 & 2.33 & 2.95 \\
\hline
\end{tabular}


Despite the fact that throughout the seasons in 2015 and 2016 most meteo conditions were associated with the effect of western circulation, the mean values of the daily mass concentration of particulate matter measured throughout three seasons in the rural areas (C) were found to be alarming. The mean value of the mass concentration of $\mathrm{PM}_{2.5}$ in the rural areas was at a similar level to the concentration of $\mathrm{PM}_{2.5}$ determined not only in Opole $\left(32.4 \mu \mathrm{g} / \mathrm{m}^{3}, p\right.$-value $\left.=0.21\right)$, but also in the towns with the highest level of pollution in Poland. At the same time, these values considerably exceeded the mass concentrations measured in the rural areas in Central and Northern Europe [6]. A statistically insignificant difference $(p$-value $=0.38)$ was also noted during the comparison of mean mass concentrations of $\mathrm{PM}_{10}$ (in Opole, it was $46.2 \mu \mathrm{g} / \mathrm{m}^{3}$ ).

The adverse aerosanitary conditions expressed in terms of the number of days when the admissible daily mass concentration of $\mathrm{PM}_{10}$ is exceeded $\left(\mathrm{C}>50 \mu \mathrm{g} / \mathrm{m}^{3}\right)$ occurred in the rural areas on average throughout 30 days of the winter season. At the same time, the arbitrarily determined condition accompanied by smog occurrence, i.e. for $C_{\mathrm{PM} 2.5}>40 \mu \mathrm{g} / \mathrm{m}^{3}$ occurred on average for the duration of 23.7 days. The data for the urban areas does not demonstrate statistically significant differences.

Figs. 1 and 2 show the values of the ratio of $\mathrm{PM}_{2.5}$ in $\mathrm{PM}_{10}$ in the urban and rural areas for the entire range of the daily data (Fig. 1), which arbitrarily confirm the condition involving smog occurrence (Fig. 2), respectively. Since the study reported here deals with mass concentrations of particulate matter in the air, the ratios registered in the two measurement spots are considered as very high. From the point of view of human health, the ratio of $\mathrm{PM}_{2.5}$ in $\mathrm{PM}_{10}$ is unacceptable. In both cases, the location of the median can suggest that the higher ratio of the fine fraction can be noted in the rural area. The value of the probability excluded this hypothesis for comparison with the data in Fig. 1 (pvalue $=0.46$ )

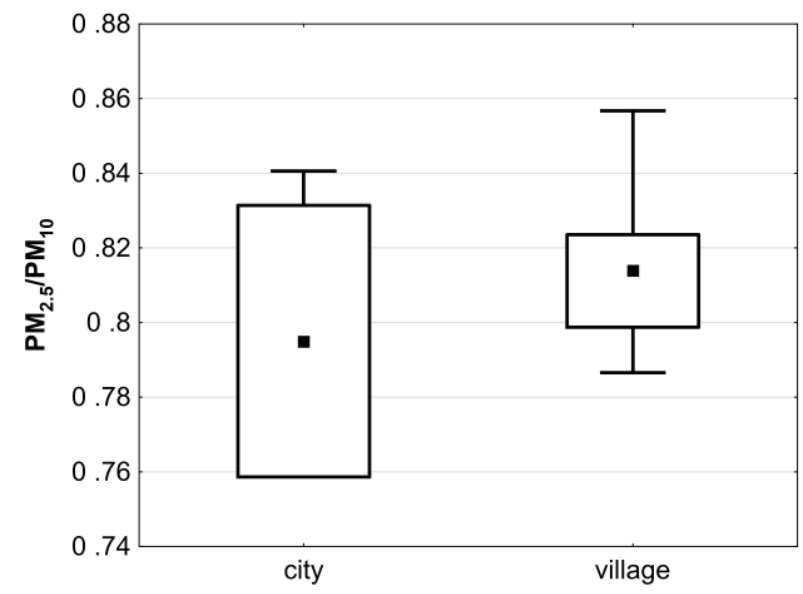

Fig. 1. Contribution of $\mathrm{PM}_{2.5}$ to $\mathrm{PM}_{10}$ (all number of observation). Boxes show the range between the $25^{\text {th }}$ and $75^{\text {th }}$ percentiles. The whiskers extend from the edge of the box to the $5^{\text {th }}$ and $95^{\text {th }}$ percentiles of the data. The squares inside indicate median values.
The phenomenon of a local concentration of particulate matter in the ambient air is very adverse. This fact is particularly attributable to the most hazardous smog component formed by fine ambient particulate matter. The results demonstrate that the human exposition in the ambient air to the most adverse aerosanitary conditions is associated with the considerably greater hazard in the rural areas. In this case, the mean ratio of $\mathrm{PM}_{2.5}$ in $\mathrm{PM}_{10}$ is nearly $10 \%$ greater and is statistically distinct from the ratio that was measured for the urban air $(p$-value $=0.03)$. The occurrence of the smog phenomenon is correlated with the increase of the respirable aerosol fraction in the suspended PM. The analysis of the 24-hour concentration of the fractions of the particulate matter demonstrates that during the episodes of smog, the ratio of $\mathrm{PM}_{2.5} / \mathrm{PM}_{10}$ was above $>0.85$. For the mean daily mass concentrations of $\mathrm{PM}_{10}$ smaller than $50 \mu \mathrm{g} / \mathrm{m}^{3}$, the mean value of this ratio was equal to 0.79 . The differences are confirmed by the results of the MannWhitney test $(p$-value $=0.002)$.

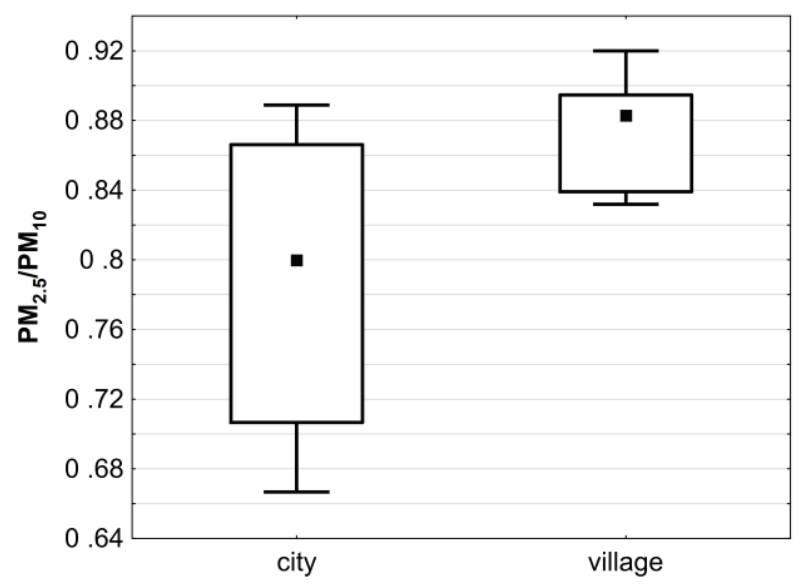

Fig. 2. Contribution of $\mathrm{PM}_{2.5}$ to $\mathrm{PM}_{10}$ (during smog occurrence).

The occurrence of the circumstances when the admissible levels of the particulate matter are exceeded was directly linked to the characteristics of the emission sources, and primarily with the intensity of the application of the thermal energy sources. This increased intensity of domestic boiler use was determined by the weather conditions.

Table 2 contains the results of the Spearman correlation between the PM's mass concentration measured at village and the remaining registered meteorological data. The analysis of correlation demonstrates that only the length of insolation does not correlate with the values of the mass concentration of particulate matter suspended in the ambient air. The results suggest that the aerosanitary conditions improve during the occurrence of precipitation similar to unstable atmosphere. An increase in the velocity of air advection, as well as the occurrence of precipitation and temperature increase affect both indirectly and directly the mass concentrations of aerosols. With the exception of wind speed and temperature, the remaining correlations are weak, though they are statistically 
significant. The results of statistical analysis correspond to literature data referred to urban area $[12,13]$ and show the main meteorological conditions that affect the modification process of an aerosanitary situation. The result of the basic analysis of the relation between he variables reveals the parameters that should be considered in the further study.

Table 2. Spearman correlation coefficient values for considered parameters.

\begin{tabular}{|c|c|c|}
\hline parameter & $\mathbf{P M}_{2.5}$ & $\mathbf{P M}_{10}$ \\
\hline $\mathrm{T}\left[{ }^{\circ} \mathrm{C}\right]$ & $-0.50^{*}$ & $-0.50^{*}$ \\
\hline $\mathrm{RH}[\%]$ & $0.22^{*}$ & $0.21^{*}$ \\
\hline $\mathrm{W}[\mathrm{m} / \mathrm{s}]$ & $-0.64 *$ & $-0.62^{*}$ \\
\hline $\mathrm{P}[\mathrm{hPa}]$ & $0.33^{*}$ & $0.36^{*}$ \\
\hline $\mathrm{R}[\mathrm{mm}]$ & $-0.33^{*}$ & $-0.34^{*}$ \\
\hline $\mathrm{Sun}[\mathrm{h}]$ & -0.01 & -0.02 \\
\hline $\mathrm{PM}_{10}$ & $0.97 *$ & 1.00 \\
\hline
\end{tabular}

*significant with $p<0.05$.

The scope of the experiment also involved the verification of the variability of the mass concentrations of the examined aerosol fractions over 60 minute intervals. The test took two weeks, including 6 days accompanied by the occurrence of a permanent temperature inversion accompanied by occurrence of smog phenomenon. Both gravimetric tests ( 24 hours) as well as optical ones (1 hour) demonstrate that enhanced by an anticyclone, the three-day period of temperature inversion occurrence caused a situation in which local air immission levels did not meet the standards required for the protection of human health.

In general, the mean daily values of $\mathrm{C}$ for $\mathrm{PM}_{2.5}$ and $\mathrm{PM}_{10}$ registered on the basis of hourly measurements were greater by $11-14 \%$ than the results that were concurrently obtained by the use of on the basis of the gravimetric analysis. By analogy, the mean ratio of the fine particles in the $\mathrm{PM}_{10}$ fraction was greater as well (0.96). The difference that was noted stems from the different approaches adopted during the measurements methodology and the determined quantities. The gravimetric analysis is based on the determination of the volume of particles in the air and measurements of the mass of particulate matter that is collected during aspiration and extracted from the filter. The mass concentration concerns only the solid particles dispersed in the air. For the case of the optical measurements, the aerosol mass is calculated on the basis of the he light beam diffusion proportionally to the particle mass passing with the air through the measurement section. The mass concentration in this case involves both the solid and liquid phase that is dispersed.

The results in Fig 3 illustrate the data derived from 36 subsequent hourly observations with regard to the parameters, which define the quality of the troposphere in the rural areas. The selected period illustrates the impact of the temperature inversion (accompanying smog, from hour 1 to $25-26$ during the observation) as well as the impact of the variability of the most relevant weather parameters. This figure demonstrates the existence of two maximums of particulate matter concentrations. It can be note, however, that these occurrences are not affected by the variations in the ambient air temperatures and wind speed. The course of the lines reflects the morning and afternoon increase of the intensity of exploitation of individual heating systems in residential buildings. Throughout the duration of the smog, the levels of hazardous substances in the air were very high. Nevertheless, the results demonstrate that the outdoor activities should be particularly avoided during the seasons corresponding to the increased exploitation of the heating systems.

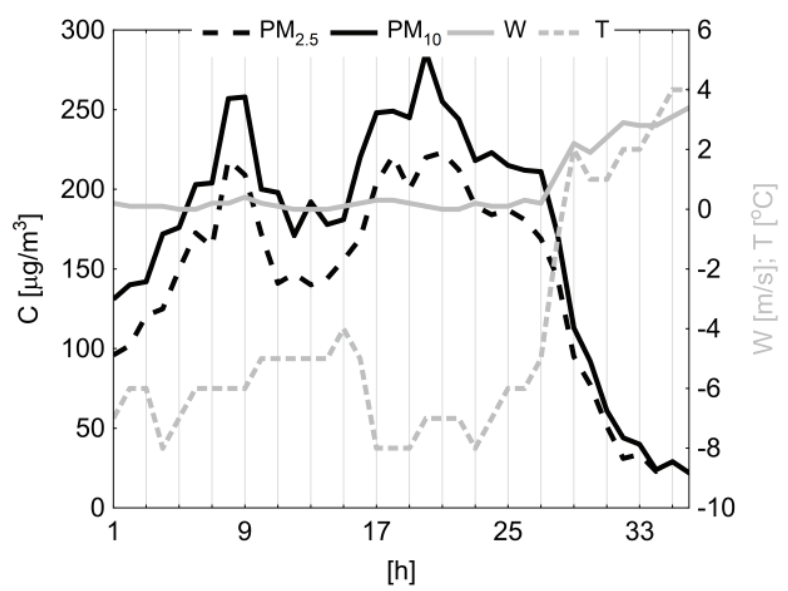

Fig. 3. Variability of selected parameters in time during and after the occurrence of temperature inversion.

Fig. 3 demonstrates that after 3 hours from the occurrence of advection movement accompanied by a concurrent considerable increase in temperature, the aerosanitary conditions considerable improve and the air quality can be considered as good as a result of the dissipation of pollutants. The change in the weather conditions determines the decrease of the intensity of the use of local, point emission sources resulting from the combustion of solid fuels, which also contributes to the improvement of ambient air quality.

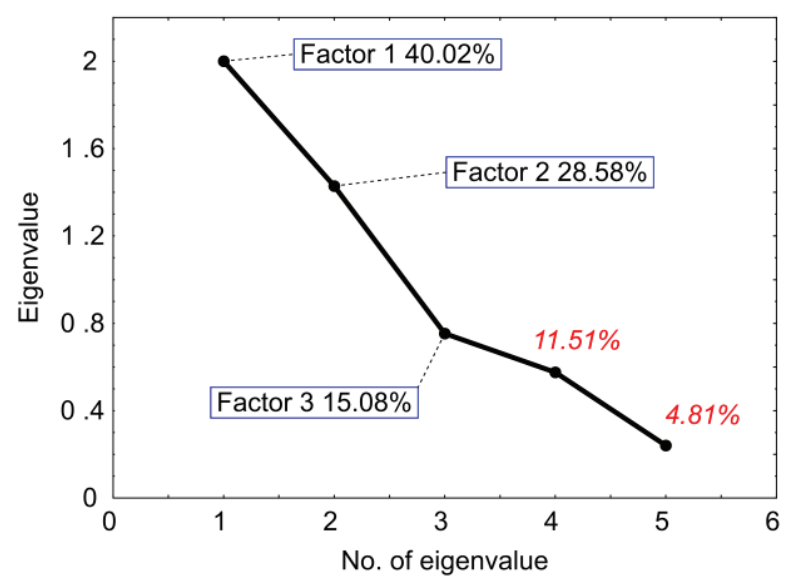

Fig. 4. PCA results. Cattell scree. 
The results of the experiment reflect the relevance of the principal components in the explanation of the relevance of the input factors (per cent in the variability in the database). The Keiser criterion was used as the principal test of the selection of the relevance parameters, which meant that the factors investigated had an eigenvalue of $>1$ [14]. The selection of the factors was also supported by the Cattell scree test $[15,16]$ (Fig. 4). The graphical interpretation indicates that in the analyzed case, three of the principal components had a decisive role. Cumulative percentage of variation explained by three components reach almost $84 \%$. Although factor no. 3 has the eigenvalue of $<1$ its impact on the justified variability of the primary data is relevant.

The relations between the primary and experimental principal components are presented in a graphical form in Fig. 5 and 6. Each of the variables is represented by a vector. The sense and length of the vector decides on the degree in which the particular variables have an impact on the values of the principal components. In the analyzed example, nearly all of the input variables are located in the vicinity of the values 1 or -1 . This means that the larger part of information contained in these variables is carried by the principal components. The fact of adjacent location of two variables indicates a strongly positive correlation. The variables located on the opposite sides are negatively correlated.

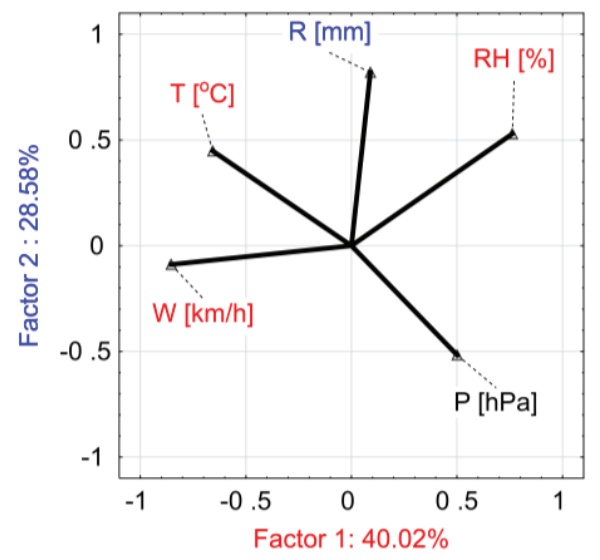

Fig. 5. The PCA results. Configuration of examined variables in the realm of factors $1-2$.

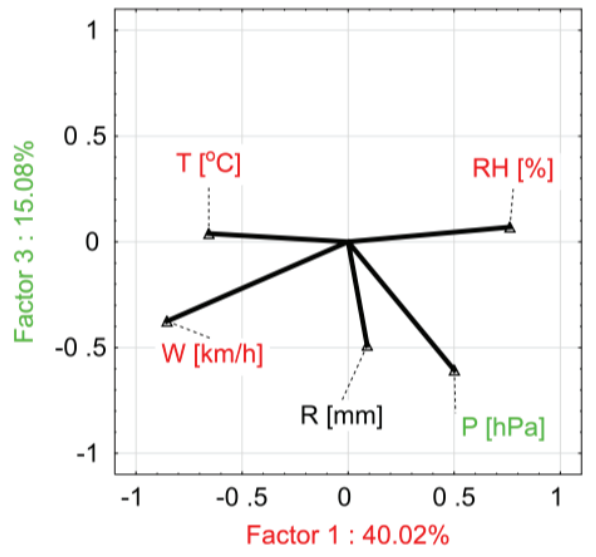

Fig. 6. The PCA results. Configuration of examined variables in the realm of factors 1-3.
The Principal Component Analysis has successfully extracted three principal components which illustrate the influence of meteorological parameters on $\mathrm{PM}_{2.5}$ and $\mathrm{PM}_{10}$ mass concentration. For the examined case, the first component is responsible for explaining $40 \%$ of information regarding the concentrations used as part of the input variables.

One can note that the principal component No.1 explains only the specific variables responsible for meteorological parameters connected with advection, air temperature and water vapor content in the air. The remaining principal components account for the variables which also describe the weather parameters; however, all of them can be considered as individual components (amount of precipitation - factor 2 and atmospheric pressure - factor 3). All of factors (common and separate components) account for over $83 \%$ of information regarding the mass concentration of considered PM's.

\section{Conclusions}

The conducted research demonstrated that throughout the winter season, the ground-level troposphere in the rural areas is considerably enriched by particulate matter emission and the values of the mass concentration of PMs does not statistically differ from the levels recorded in the urban areas. The values of the daily and hourly mass concentration of $\mathrm{PM}_{2.5}$ and $\mathrm{PM}_{10}$ are very improper. The ratio of the fine particles in the particulate matter suspended in the air, whose hazard to human health is known to be high, is greater in the rural areas than in the towns for the case of the occurrence of smog which is boosted by the temperature inversion phenomenon. The analysis of the main components revealed that the metrological factors play a critical role on the ambient air quality. In the cold season, the control of air quality is performed by the temperature, which determines the level of pollution. An increase of this parameter leads to the smaller utilization of the domestic boilers. The occurrence of the advection and precipitation as a result of the changes in atmospheric pressure leads to the local dilution of particulate matter in the ground-level ozone even in the areas characterized by the considerable emission of pollution of anthropogenic origin.

It seems, that the results cannot be supra-local dimension. But they can find confirmation of areas with similar characteristics of emission and climaticmeteorological conditions. At the local scale, the results of the experiment show that it is necessary to replace old heating systems with new ones that do not generate significant amounts of dust. As a consequence, there is the necessity of implementing immediate change in the Polish legislation.

\section{References}

1. J. Schwarz J., M. Cusack, J. Karban et al., Atmos Res 176-177 (2013)

2. J. Krynicka, A. Drzeniecka-Osiadacz, Pol. J. Environ. Stud. 22 (4) (2013) 
3. Z. Mijić, A. Stojić, N. Perisić, M.,Rajsić, S. Tasić, M. Radenković, J. Joksić, Atmos. Environ. 44 (2010)

4. T. Olszowski, Proscince 1 (2014)

5. K.M. Nam, N.E. Selin, J.M. Reilly, S. Paltsev, Energy Policy 38 (2010)

6. W. Rogula-Kozłowska, G. Majewski, B. Błaszczak, K. Klejnowski, P. Regula-Kopiec, Int. J. Environ. Res. Pub. Heal. 13 (2016)

7. http://www.opole.pios.gov.pl:81 (acces 10. 07. 2017)

8. EN 12341:2014.

9. www.tsi.com (acces on 10.07.2017)

10. M. John, C. E. Priebe, Comput. Stat. Data Anal. 51(9) (2007)

11. I.T. Jolliffe, Principal Component Analysis (Springer-Verlag, New York, USA,1986)

12. S. Hormann, B. Pfeiler, E. Stadlober, Austrian J. Stat. 34(307) (2005)

13. E. Maraziotis, L. Sarotis, O Marazioti, P. Marazioti, Glob NEST J. 10 (2008)

14. A.R. Ferro, R.J. Kopperud, L.M. Hildemann Environ Sci Technol. 38 (2004)

15. H.F. Kaiser, Edu Psych Meas. 20 (1960)

16. R.B. Cattell, Multivar Beh Res. 1 (1966) 